\title{
Two Structures for Compositionally Derived Events
}

\author{
Beth Levin and Malka Rappaport Hovav \\ Northwestern University and Bar Ilan University
}

This paper addresses the phenomenon of event composition: the derivation of a single event description expressed in one clause from two lexical heads which could have been used in the description of independent events, each expressed in a distinct clause. In English, this phenomenon is well attested with respect to sentences whose verb is found in combination with an XP describing a result not strictly lexically entailed by this verb, as in (1).

(1) The joggers ran the pavement thin.

This sentence makes reference to a complex event encompassing an event of running and an event of becoming thin. The lexical heads run and thin appear in a single clause, with the AP appearing as closely bound to the verb in the syntax as subcategorized complements (Levin and Rappaport Hovav 1995; Tenny 1994; Roberts 1988), justifying the assumption that a single event is made reference to by this sentence. We consider (1) to be an instance of event composition since its verb, run, on its own does not entail a particular result state, and certainly not a result state that does not involve the runner. Furthermore, the components of the event described in this example could have been expressed in separate clauses, as in The joggers ran and they caused the pavement to become thin or as in The joggers caused the pavement to become thin by running.

We address two major questions concerning event composition. ${ }^{1}$ The first is: What relation must hold between two events in order for the event structures representing them to be able to be composed into one event structure expressible in a single clause? The second is: What is the nature of the event structures of compositionally derived events?

It has been claimed that only causally related events can be composed (e.g., Croft 1991; Gawron 1985; Kaufmann 1995b; though see Wunderlich 1997a, 1997b, who proposes that contemporaneous events can also be composed). As a consequence, it is also frequently assumed that event composition results in the linguistic event structure of a causative verb. Causative event structures are distinctive in that they are composed of two subevents, each of which can itself stand alone as a well-formed event structure, contrasting with simple event structures, which consist of only a single subevent. Surprisingly, there has been little discussion of exactly what criteria make a causative, rather than a simple, event structure appropriate for compositionally derived events.

In this paper, we present evidence from the syntax of nonlexically entailed result XPs in English that although many instances of event composition yield a causative event structure, in other instances a simple event structure is more appropriate. We show that in those instances where a simple event structure is preferable, the semantic relation between the components of the compositionally derived event is tighter than the relation which holds between the components of a causative event 
structure. We suggest that in the first case the two composed events meet conditions on event identity discussed in the philosophy and linguistics literatures, and we propose that when these conditions are met the two events are, in our terms, COIDENTIFIED, giving rise to the simple event structure. We discuss the nature of event coidentification and suggest that event coidentification takes place due to Gricean considerations.

\section{Nonlexically Entailed Result XPs in English}

English allows XPs denoting nonlexically entailed results to be added to verbs, giving rise to what is usually referred to as the resultative construction. Several types of resultative constructions are illustrated in (2)-(4); another is introduced in section 2.2. In each example in (2)-(4) there is an NP and an XP following the verb; the XP is predicated of the NP and specifies the result state of the NP as a consequence of the event described by the verb.

(2) a. Kelly wiped the table clean.

b. The mother rocked the baby to sleep.

c. The blacksmith hammered the metal flat.

(3) a. Sam coughed himself into a haemorrhage.

b. They yelled themselves hoarse.

c. He'd rock and chant himself into a trance.

(4) a. The joggers ran the pavement flat.

b. He sang us all to sleep.

c. The dog barked the neighbor awake.

The resultatives in (2) are based on transitive verbs and the postverbal NP is subcategorized by the verb. For example, in (2a) Kelly wipes the table with the result that the table is clean. The other two sets of examples illustrate resultatives based on intransitive verbs; in (3) the verb is followed by a reflexive pronoun and in (4) by a nonreflexive NP. In neither set is the postverbal NP selected by the verb; that is, corresponding to ( $3 a$ ) there is no sentence *Sam coughed himself and corresponding to (4a) there is no sentence *The joggers ran the pavement. The postverbal NP, then, must be licensed by the result XP. We refer to the resultatives illustrated in (3) as reflexive resultatives, and those in (4) as nonsubcategorized NP resultatives. In the reflexive resultatives, the use of a reflexive pronoun which is coreferential with the verb's subject allows the result XP to be understood as predicated of the subject. In fact, since this reflexive pronoun appears not to have an independent semantic function it has sometimes been referred to as a "fake" reflexive (Simpson 1983).

Resultatives are often analyzed as describing single but complex events, typically causatives, consisting of a causing subevent and a result subevent brought 
about by the causing subevent (Carrier and Randall 1993; Jackendoff 1990; Kaufmann and Wunderlich 1998; Rappaport Hovav and Levin 1998; Van Valin 1990; among others). The causing subevent is expressed by the verb, and the state or location that results from the event described by the verb is expressed by the added XP. There have been a variety of motivations discussed for considering resultatives to be causatives (see, for example, Carrier and Randall 1993; Dowty 1979; Goldberg 1995; Jackendoff 1990; McCawley 1971); most obvious among them is the fact that resultatives can easily be given a causative paraphrase. Thus, They yelled themselves hoarse can be paraphrased as Their yelling caused them to become hoarse.

In this paper, we focus on the event structures associated with resultatives based on intransitive verbs, and, in particular, on the event structures associated with the reflexive resultative pattern and another pattern, the bare XP pattern to be introduced in section 2.2. We limit ourselves to these two types of resultatives because the contrasts between them can be effectively exploited in an investigation of the nature of compositionally derived events; however, the results described for these types of resultatives can be extended to all resultatives, including nonsubcategorized NP resultatives and resultatives based on transitive verbs. We briefly return to nonsubcategorized NP resultatives in note 6 and transitive verb-based resultatives in section 2.3; see also Rappaport Hovav and Levin 1999 for more discussion.

We now turn to an investigation of the appropriate event structures for the two types of intransitive verb-based resultatives that are the focus of our study. Our arguments for their event structures draw on the results of research on the mapping from event structure to syntax which show that the syntax of resultative constructions can be used to argue for their associated event structure.

\section{Complex and Simple Event Structures}

We begin this section by introducing an argument for assigning a causative event structure to reflexive resultatives that has not been discussed previously in the literature. We show that a causative event structure for such resultatives can provide an explanation for the appearance of the "fake" reflexive following intransitive verbs in these resultatives. In section 2.2 we show that the lack of a reflexive pronoun in yet another type of intransitive verb-based resultative-bare XP resultatives-can be used to argue against a causative event analysis of this second type of resultatives. In this section we also present independent evidence that supports our proposal that a causative event analysis is not appropriate for bare XP resultatives. In section 2.3 we show the semantic basis for the distinction between those resultatives which are associated with a causative event structure and those which are associated with a simple event structure, showing that the temporal relation between the subevents in the two cases is different. As we show in section 2.4, this temporal relation provides further justification for the causative analysis of reflexive resultatives since the constraints on the relation between the subevents in reflexive resultatives are identical to the constraints on the relations between the subevents of well-established lexical causatives. 


\subsection{Argument Realization Reflects Event Complexity}

Events can be characterized according to whether their linguistic representations are complex, consisting of two subevents, each of which can stand alone as a well-formed event structure, or simple, consisting of a single subevent. The representations in (5) are taken from Rappaport Hovav and Levin 1998, but the complex/simple event dichotomy is evident in other proposed event structure representations which may differ from these in various respects (e.g., Parsons 1990; Pustejovsky 1991, 1995; Van Valin and LaPolla 1997). ${ }^{2}$

$$
\begin{array}{ll}
\text { a. } & {[\mathrm{x} \text { ACT }<M A N N E R>]} \\
\text { b. } & [\text { [ } \mathrm{x} \text { ACT }] \text { CAUSE }[\operatorname{BECOME~}[\mathrm{y}<S T A T E>]]]
\end{array}
$$

The representation in (5a) is a simple event structure for an activity, but states and changes of state also have simple event structures. The representation in $(5 \mathrm{~b})$ is the bipartite representation associated with complex causative events, with two subevents; we take all complex events to be causatives, and we will use the terms complex event structure and causative event structure interchangeably.

Recently several researchers have suggested that the complexity of event structure is reflected in the argument realization options for complex and simple events (e.g., Grimshaw and Vikner 1993; van Hout 1996; Kaufmann and Wunderlich 1998; Rappaport Hovav and Levin 1998). In particular, one effect of the wellformedness conditions on the mapping from event structure to syntax introduced in Rappaport Hovav and Levin 1998 is that there must be at least one distinct argument $\mathrm{XP}$ expressed in the syntax per subevent in the event structure, what we call here the Argument-Per-Subevent Condition. ${ }^{3}$ As a consequence, argument realization patterns reflect the complexity of the events being described, so that verbs in sentences expressing causative events must have at least two arguments and, thus, are obligatorily transitive. Rappaport Hovav and Levin (1998) show that this assumption explains a range of differences in the argument expression options available to verbs of surface contact and motion (e.g., wipe, rub, scrub, sweep), which are chosen to represent verbs with simple event structures, and lexically simple externally caused verbs of change of state (e.g., break, dry, open), which are chosen to represent verbs with complex event structures.

The examples in (6) show that verbs of surface contact and motion can appear without overt direct objects in nongeneric, nonhabitual contexts, while verbs of change of state cannot.

a. Leslie swept (the floor).

b. $*$ Kelly broke again tonight when she did the dishes.

Rappaport Hovav and Levin explain this difference by arguing that verbs of surface contact and motion, as activity verbs, are associated with a simple event structure, even though they describe events with two participants (an agent and a surface). Due to their simple event structure, one of their arguments may be left unexpressed 
without violating the Argument-Per-Subevent Condition; whether the argument actually can be left unexpressed depends on whether the pragmatic conditions necessary for the interpretation of an unexpressed object are satisfied. It is the interaction of the Argument-Per-Subevent Condition and these pragmatic conditions that give rise to the "unspecified object" interpretation associated with the intransitive use of verbs of surface contact and motion. In contrast, externally caused verbs of change of state, as causatives, are associated with a complex event structure with two subevents and must express both their arguments in order for the ArgumentPer-Subevent Condition to be satisfied. Thus, these verbs do not permit intransitive uses with an unspecified object interpretation. ${ }^{4}$

The data in (7) shows that verbs of surface contact and motion can appear in sentences with a complex event structure, where the event described by the verb brings about the achievement of the state described by the added XP, but that verbs of change of state cannot.

(7) a. The child rubbed the tiredness out of his eyes.

Cinderella scrubbed her hands raw.

b. $\quad *$ The clumsy child broke the beauty out of the vase.

* The clumsy child broke his knuckles raw.

What is striking about the examples in (7) is that the direct object does not correspond to the second argument of the verb, but rather to a newly introduced argument which is the "subject" of the achieved state expressed by the introduced XP. This option is allowed for verbs of surface contact and motion, but not for externally caused verbs of change of state, since the former, as activity verbs, satisfy the ArgumentPer-Subevent condition even when only one of their arguments is expressed, while verbs of change of state must express both their arguments to meet this condition. Thus, other than "normal" objects are permitted with verbs of surface contact and motion, but the choice of object is fixed for verbs of change of state.

The hypothesis that a complex event structure must be associated with two argument XPs in the syntax, one for each subevent, has consequences for argument expression in resultatives. If reflexive resultatives based on intransitive verbs have a complex event structure, then by the Argument-Per-Subevent Condition they must include an object in order for the second subevent in this event structure to have an associated argument XP. That is, if the event structure associated with the reflexive resultative (8) is complex, then there must be distinct argument XPs in the syntax for each of the subevents in the event structure: one for the subevent represented by the verb and one for the subevent represented by the XP.

Terry yelled himself hoarse ... (M. Maron, Southern Discomfort, The Mysterious Press, New York, 1993, p. 66)

In fact, there are two distinct argument XPs in (8); however, the argument XP which represents the participant in the result subevent is expressed as a reflexive because it has the same referent as the subject argument XP. Although the reflexive has the same referent as the subject, it cannot be omitted as it is required by the ArgumentPer-Subevent Condition (*Terry yelled hoarse). Thus, the label "fake" that has 
been applied to the reflexive on the assumption that it is a syntactic placeholder is a misnomer.

\subsection{The Bare XP Resultative Pattern: The Case for a Simple Event Structure}

A reflexive pronoun is not always required when a result $\mathrm{XP}$ is combined with an intransitive verb to form a compositionally derived event. Intransitive verbs are found in another resultative pattern, illustrated in (9), where result XPs are predicated directly of their subjects without the mediation of reflexives. Due to this salient characteristic, we call this resultative pattern the bare XP pattern.

a. ... the cookies ... had burned black ... (P. Orenstein, "Almost Equal," The New York Times Magazine, April 5, 1998, p. 48)

b. This time the curtain rolled open on the court of the Caesars ... (Olivia, Olivia, Hogarth Press, London, 1949, p. 35)

c. I ... sloshed through the rain to the magazine's office in Kendall Square. (S. Kelly, Out of the Darkness, Villard, New York, 1992, p. 4)

d. Sitting with our damp outer clothes steaming dry on the radiators ... (N. Edwards, Mud, The Women's Press, London, 1986, p. 38)

e. If kettle is allowed to boil dry, damage may occur to porcelainized coating. (brochure included with Copco Tea Kettle)

f. The branding iron burned into the calf's skin. (Croft 1991:161, (25))

If the presence of the reflexive can be taken to support the causative event structure associated with the reflexive pattern, then the absence of the reflexive in the bare XP pattern can be taken as evidence that such resultatives are associated with a simple event structure rather than a causative event structure with two subevents. Only in this way would the absence of the reflexive be allowed.

The bare XP pattern has not received the same attention as the other resultative patterns, nor has it received a consistent analysis. In fact, some researchers have even denied that this pattern represents a subtype of the resultative construction. ${ }^{5}$ Kaufmann (1995a), Pustejovsky (1991), and Rapoport (1998), among others, have argued that what we label bare XP resultatives are semantically distinguished from other resultatives in that their result XPs denote the endpoints of changes of state that are already lexicalized in their verbs. That is, they cite examples such as those in (10), pointing out that bursting necessarily entails opening and freezing necessarily entails becoming solid.

(10) a. The bag burst open.

b. The pond froze solid.

Although this observation may be true of these examples and possibly also of (9a), it certainly does not hold of most of the examples in (9), which contain nonlexically 
entailed result XPs. For example, the verbs roll, slosh, and steam in (9b)-(9d), are atelic and do not lexically entail a result state. In $(9 \mathrm{e})$, the verb boil is used in the sense 'be in the state of boiling', rather than the sense 'come to boil'. This sense is atelic, as evidenced by the acceptability of a durative adverbial in The kettle boiled for five minutes, and does not entail that a state of dryness will come about. Finally, although (9f) describes a change of location, the verb burn, whatever its basic aspectual properties, does not entail a change of location. Thus, these bare $\mathrm{XP}$ resultatives are instances of what we term event composition.

Nevertheless, certain bare XP resultatives have sometimes been given a causative analysis, associating them with the same complex event structure as reflexive resultatives. In particular, causative analyses have been proposed for those bare XP resultatives which involve verbs of manner of motion in combination with a PP describing the goal of motion and date back at least to Kenny (1963:177), who writes "walking to Rome is bringing it about that I am in Rome." More recently, Croft (1991:160) explicitly suggests that there is a causal relation between the subevents of such resultatives, offering the paraphrase 'the activity of sailing causes the motion to come about' for The boat sailed into the cave, while Van Valin (1990:224, (3d)) provides the causative representation in (11) for Susan ran to the house.

[run'(Susan)] CAUSE [BECOME be-at'(house, Susan)]

As Kenny's and Croft's paraphrases suggest, it is possible to isolate a causing event and a result event in certain bare XP resultatives. The availability of such paraphrases may perhaps explain why such bare XP resultatives are sometimes given a causative analysis and, hence, a complex event structure. This proposal may also have its origins in the observation that many bare XP resultatives share certain aspectual properties - in particular, their durativeness and telicity-with prototypical accomplishments, such as Kim built the tree house. In his book Word Meaning and Montague Grammar, Dowty (1979) entertains the possibility that the class of accomplishments can be equated with the class of causatives, and indeed he makes a preliminary suggestion to this effect in Chapter 2 of his book (p. 91). But his revised aspectual classification in Chapter 3, which derives the temporal properties of the various classes from his interval semantics, does not give a uniform representation to all accomplishments, and the predicate CAUSE is no longer used to capture temporal properties. Nevertheless, there has been a tendency to equate accomplishments with causatives in subsequent studies, such as those cited above. Recently, however, Van Valin and LaPolla (1997:101) have argued that those instances of the bare XP pattern that take the form of a verb of manner of motion plus a goal phrase should not be given a causative analysis, and as mentioned here, the absence of the reflexive in this pattern-which supports a simple event structure analysis-can be taken as further evidence in support of their position.

We now briefly review additional reasons for believing that a complex event structure is not appropriate for the bare XP pattern, but rather a simple event structure analysis is preferable, even for those instances of the pattern with nonlexically entailed result XPs. First, as already mentioned, bare XP resultatives such as those 
in (10) show no evidence of event composition, consisting simply of a single event, since their result XP specifies or modifies the endpoint of a scale already lexicalized in the verb and does not introduce a nonlexically entailed result. In fact, such bare XP resultatives cannot be given paraphrases that make explicit reference to two events (cf. Parsons 1990), as illustrated in (12).

(12) a. The pond froze solid. $\neq$ 'The pond got solid/solidified by freezing.'

b. $\quad$ The bottle broke open. $\neq$ 'The bottle opened by breaking.'

In contrast, bare XP resultatives that clearly involve event composition, as evidenced by the fact that they involve nonlexically entailed results, allow such paraphrases. For example, the bare XP resultatives in (13) allow the paraphrases in (14). In these paraphrases the by-phrases appear to make direct reference to entities which can only be classified as events. Thus, these paraphrases, then, can be said to make explicit reference to two events.

(13) a. Casey waltzed out of the room.

b. The clothes steamed dry.

(14) a. Casey went out of the room by waltzing.

b. The clothes became dry by steaming.

Taking the uniform syntactic structure of bare XP resultatives with and without nonlexically entailed result XPs together with the principles of event structure-tosyntax mapping elaborated in section 2.1 , it seems reasonable to assume that both subtypes of bare XP resultatives are associated with the same, simple event structure. The challenge for us will be to reconcile the idea that these instances involve event composition with the idea that they involve a simple event structure.

Second, the relation between the subevents in bare XP resultatives is less uniform than in reflexive resultatives. In bare XP resultatives the verb does not consistently express the cause, nor the XP the result. In contrast, in reflexive resultatives (and also transitive verb-based resultatives and nonsubcategorized NP resultatives), the verb uniformly represents the causing event and the result XP represents the result event. Thus, in Kelly yelled herself hoarse, the yelling is the causing event and the becoming hoarse is the result event. Although many bare XP resultatives follow this pattern, it does not readily extend to most bare XP resultatives based on verbs of sound emission with goal result XPs. Contrast the bare XP resultative headed by a verb of manner of motion and the one headed by a verb of sound in (15).

(15) a. Terry ran into the room.

b. Terry rustled into the room.

In (15a) the running causes the movement into the room, so that the verb expresses the cause and the XP the result, as in reflexive resultatives. In (15b), the movement into the room causes the rustling - the emission of the sound denoted by the verbso it is the XP that expresses the cause and the verb that expresses the result, as 
also noted by Goldberg (1995). Thus, in the bare XP pattern there is no consistent correspondence of cause and result with verb and XP. We suggest that this lack of uniformity supports a simple event structure for bare XP resultatives. If two subevents are not represented in the event structures of such resultatives, then there may be no reason that particular meaning components need to be associated with particular lexical items as long as the appropriate set of meaning components is associated with the event as a whole. In contrast, a complex event structure with two distinct subevents, each with a fixed meaning and expression, would not be able to show this flexibility.

Based on these pieces of evidence, we propose that a simple event structure analysis is valid for all bare XP resultatives, even those including a result XP that is not lexically entailed by the verb. Two questions then arise. First, when does the addition of a nonlexically entailed result to an intransitive verb yield a simple event structure and when does it yield a complex event structure? Second, if bare XP resultatives involve event composition but not a complex event structure, then how does the simple event structure arise? We address the first question in section 2.3 by examining what differentiates the two types of resultatives. In section 3 we return to the second question - the question of what kind of event structure to assign to the bare XP pattern-building on our answer to the first question.

\subsection{The Distinct Temporal Structure of the Two Resultative Patterns}

We propose that the difference between the reflexive and bare XP resultatives has its root in a difference in the temporal relation between the constituent events. The temporal relation between the event described by the verb-the causing subeventand the achievement of the state/location described by the result XP-the result subevent-in the reflexive pattern is different from that in the bare XP pattern.

In bare XP resultatives the temporal progress of the event described by the verb is necessarily dependent on the temporal progress towards the achievement of the state described by the result XP; by this we mean that the subevents are temporally coextensive and unfold at the same rate. Thus, the event described by the verb begins when the progress towards the result begins, and it necessarily extends until the result is achieved. In (16), for example, the dancing begins when Tracy starts across the ballroom and must continue until Tracy reaches the other side of the ballroom.

Tracy waltzed to the other side of the ballroom.

Adverbial modification can be used to demonstrate the temporal dependence of the subevents in bare XP resultatives. A rate adverbial inserted into such a resultative modifies both subevents. Thus, (17) entails that the pony both went to the other side of the field slowly and trotted slowly. This sentence cannot receive an interpretation where the progress across the field was slow, but the trotting was quick.

The pony slowly trotted to the far side of the field. 
Furthermore, (18) gives the impression of being a contradiction, as expected if the two subevents in the first clause, a bare XP resultative, are temporally dependent.

(18) Lewis ran quickly to the theater, but it took him a long time to get there since he took a circuitous route.

If the two subevents were temporally independent, it should be possible for the adverbial quickly to modify only one of the subevents, say the running, allowing for a second temporal phrase to independently specify information about the amount of time it takes to reach the destination (a long time), as (18) does. However, the observation that this sentence is contradictory shows that the adverbial applies to both the running and the going to the theater-they are understood to be both simultaneous and quick - and this is incompatible with the temporal extent phrase ( $a$ long time), which specifies that the process of getting to the theater was nevertheless extended in time. This observation is reinforced, when (18) is contrasted with (19), which is not understood to be a contradiction, presumably because the two events, that of running and that of getting to the theater, are encoded in different clauses, and hence are not constrained to be temporally dependent.

(19) Lewis ran quickly, but it took him a long time to get to the theater since he took a circuitous route.

Aspectual considerations provide further evidence for the temporal dependence of the subevents in the bare XP pattern. In this pattern, the lexical aspect of the verb is reflected in the interpretation of the result XP and thus determines the lexical aspect of the sentence as a whole. This interdependence is expected if both subevents comprising the event as a whole unfold together. Consider the pair of sentences in (20), which both involve the same XP, but differ in their verbs. In (20a), where the verbs are durative, the achievement of the result state is protracted, and the event as a whole has duration, but in (20b), where the verbs are punctual, the achievement of the result state must be close to punctual and so is the event as a whole. Closing an aperture can be done quickly or slowly, and the different rate at which it happens in these sentences reflects the lexical aspect of the verb.

(20) a. The gate (slowly) creaked/rumbled shut.

b. The trapdoor (*slowly) banged/thudded shut.

In contrast, in reflexive resultatives the temporal progress of the event described by the verb need not be dependent on the temporal progress towards the achievement of the state described by the result XP. The subevents need not be temporally coextensive, nor need they unfold at the same rate. These properties are illustrated in (21), which clearly describes an event where the result state is achieved after the conclusion of the causing event. ${ }^{6}$

(21) Robin danced energetically during the party Sunday night. When she woke up stiff on Monday, she said: "I guess I've danced myself stiff." 
In such resultatives, even when the subevents are coextensive, this is accidental. Thus, it is possible that in Robin danced herself stiff the getting stiff happens to begin when the dancing starts and happens to culminate when the dancing ends, but the two events do not have to unfold together, as (21) shows. It appears that the nature of the event named by the verb and the nature of the result named by the XP jointly determine whether the two events must inherently be coextensive and do not just happen to allow accidental coextensiveness.

Additional evidence that the subevents in reflexive resultatives need not be temporally dependent comes once again from adverbial modification. In contrast with bare XP resultatives, adverbials need not modify both subevents in reflexive resultatives. Thus, (22) entails that Peter quickly developed an inferiority complex, but it need not entail that he read quickly, as brought out by the felicity of a continuation that explicitly states the reading was slow, as shown in (23).

Peter quickly read himself into an inferiority complex.

(23) Peter quickly read himself into an inferiority complex, after a few slow deliberate readings of his classmates' theses.

Furthermore, in reflexive resultatives the lexical aspect of verb is not necessarily reflected in the aspect of the event introduced by the result XP. Thus, although the verb cough is a semelfactive and can be used punctually, the use of the matrix verb wait in (24) explicitly asserts that the event described by the reflexive resultative has duration, precluding a reading where there is a single cough and forcing an interpretation where there is an iterated series of coughs. Nevertheless, this example is certainly compatible with a reading in which, following a series of coughs, the car came to life with a sudden start, so the achievement of the result state is nevertheless punctual. Thus, the temporal contours of the event introduced by the verb and of the result subevent need not be the same.

... I waited for the Jetta to cough itself awake. (V. Wilson Wesley, No Hiding Place, G.P. Putnam's Sons, New York, 1997, p. 171)

As we show in more detail in Rappaport Hovav and Levin 1999, the key role of temporal dependence in the analysis of resultatives based on intransitive verbs is reinforced by an examination of resultatives based on transitive verbs. Such resultatives can also be classified according to whether they involve subevents that are necessarily temporally dependent, as in The lifeguard pulled the man out of the water, or subevents that need not be temporally dependent, as in The critics panned the play right out of town. Furthermore, the verbs that head transitive resultatives with temporally dependent subevents-verbs of exerting force such as pull, tug or yank-have an additional noteworthy property. They are not found in the double object construction (*The lifeguard pulled the mother the baby), although semantically close verbs are. This restriction has been attributed by Pesetsky (1995) and Pinker (1989) to the fact that these verbs describe the simultaneous displacement of a physical object and exertion of force on this object-another way of describing 
temporally dependent subevents. Thus, temporal dependence figures in the characterization of linguistic phenomena other than the resultative construction.

As mentioned above, the inherent nature of the relation between the event described by the verb and the event of achieving the state described by the result XP determines whether or not the two events are necessarily temporally dependent. Although we have not yet been able to formulate an explicit characterization of what makes this relation between two events hold, it is clear that certain pairs of events must show this dependence. For example, when a particular manner of motion is the means of traversing a path as in The boat sailed into the cave or Robin danced out of the room, the movement and the traversal of the path are necessarily temporally dependent since as the motion continues the path is traversed. Nevertheless, it is possible that certain pairs of events might be construable as either temporally dependent or temporally independent; if so, we predict that the different construals would have distinct syntactic encodings determined by the relation between the subevents. This prediction is realized, as demonstrated by the minimal pairs in (25)-(26). The members of each pair have the same verb-result XP combinations and thus involve the same subevents, but they differ as to whether they are bare XP resultatives, as in the (a) sentences, or reflexive resultatives, as in the (b) sentences.

(25) a. One woman gets up to leave, but Red-Eyes grabs her roughly by the arm and pulls her into his lap. She wriggles free ... (F. O'Reilly, "Killing Time in the Shadow of War," The Ottawa Citizen, November 30, 1997, p. D10)

b. "As he was entering the lift he was struck on the shoulder by the door and became stuck," Ms Romeril said. "Mr Duggan became alarmed about being caught in the door of a lift which was about to begin its descent and wriggled himself free." ("Historian Settles Action on Lift Incident," The Irish Times, December 2, 1994, p. 4)

(26) a. On the way to the speedway, one of his race cars wiggled loose inside the transporter and caused damage to both of his cars. (S. Rose, "Robby Gordon Finds Problems Again at Track," The Kansas City Star, August 1, 1997, p. D11)

b. "I had it [=the snake] pinned and when I lifted it up into the bag, it wiggled itself loose and just sank its fangs on my knuckle" ... (M.E. Fernandez, "No Bark, But Big, Big Bite," The Washington Post, July 11,1998 , p. C03)

The members of each pair show a difference in meaning consistent with the expected difference in whether or not the subevents are necessarily temporally dependent. (We return to comparable minimal pairs where this difference in construal may not be found in section 4.) In the scenario in (26a), which is expressed by a bare XP resultative, the restraints holding the car in place loosen little by little from the continual wiggling of the car inside the moving truck. The two events are coextensive and unfold together: as the wiggling continues, the loosening continues. 
Thus, these events manifest the temporal dependence characteristic of a bare XP resultative. On the other hand in (26b), which uses a reflexive resultative, although the snake's wiggling and getting loose could proceed in tandem, it is more likely that the snake wiggles until suddenly the person holding the snake loosens his or her grip. Thus, the events need not unfold together. In fact, when wiggling is used to bring about a state that is not a necessary result of wiggling, so that the events cannot be necessarily temporally dependent, then a reflexive resultative is required, as shown in (27). Getting comfortable is a matter of trial and error, and thus the achievement of this state cannot be temporally dependent on the wiggling.

(27) a. I tried to wiggle myself comfortable in the passenger seat. (L. Barnes, Hardware, Delacorte, New York, 1995, p. 35)

b. $*$ I tried to wiggle comfortable in the passenger seat.

The minimal pairs in (25)-(26) pose a problem for many previous accounts of resultatives, which posit that the nature of the verb and the semantic type of the $\mathrm{XP}$ together determine the syntactic pattern of the resultative the verb-XP combination can be found in. These previous accounts (e.g., Bresnan and Zaenen 1990; Hoekstra 1984, 1988; Levin and Rappaport Hovav 1995) tie the syntax of the construction to the classification of the verb as unaccusative or unergative, and the classification of a particular verb can sometimes vary according to the semantic type of the XP. The minimal pairs are problematic because they preserve the same verb-result XP combination while differing as to the presence or absence of a "fake" reflexive. See Rappaport Hovav and Levin 1999 for further discussion.

\subsection{Further Support for the Causative Analysis of Reflexive Resultatives}

We have argued that reflexive resultatives should be assigned a causative event structure based on their pattern of argument expression. Most commonly, this event structure is associated with lexical causatives, that is, with verbs such as kill and transitive break or open whose meaning is paraphrasable using a notion of cause. If lexical causatives are associated with the same event structure as reflexive resultatives, we would expect them to manifest the same temporal relation between their subevents as reflexive resultatives do, assuming that this relation is a characteristic of a causative event structure. And indeed, the two subevents in a lexical causative are not necessarily temporally dependent, as the following examples show.

(28) a. Casey's piano playing woke the baby.

b. Terry shocked Sandy by deciding to run for office.

c. The widow murdered the old man by putting poison in his soup.

In (28a) the causing subevent, the piano playing, may go on for some time, but the result subevent, the baby's awakening, may be punctual (though it need not be). In (28b), Terry's decision to run for office could have occurred well before Sandy hears of it. In (28c) the act of poisoning the soup must precede its ingestion by the victim and thus the victim's death. 
In fact, lexical causatives and reflexive resultatives impose several additional but common constraints on the relationship between their subevents; these are given in (29).

(29) a. The result subevent cannot begin before the causing subevent.

b. The result subevent must bound the event as a whole.

c. The result subevent would not have happened if the causing subevent had not happened and all else had remained the same.

d. There is no intervening event in the causal chain between the causing subevent and the result subevent.

The first two constraints simply reflect the nature of what we have called causing and result subevents. We take the third constraint-the counterfactual relation between the subevents - to be the defining property of being a causative event, following the discussion in Dowty 1979, who in turn draws on Lewis 1973. We give the constraint in this form for simplicity, although ultimately it will need to be refined, most likely along the lines laid out in Dowty 1979:109. Studies of causatives have shown that the type of causation expressed in lexical causatives is what has been called direct causation (McCawley 1978; Pinker 1989; Shibatani 1976b; among others), and Goldberg (1995) also argues that resultatives involve direct causation. We propose that the constraint in (d) ensures that the relation between subevents is indeed a relation of direct causation. These shared constraints further support the assignment of the same event structure to both reflexive resultatives and lexical causatives.

\section{Bare XP Resultatives: An "Event Coidentification” Analysis}

We now return to the question of the appropriate event structure for those instances of the bare XP pattern with nonlexically entailed results. The problem that needs to be resolved is that, as established in section 2.2, the syntactic form of these bare $\mathrm{XP}$ resultatives suggests a simple event structure consisting of a single subevent, yet, as also argued in section 2.2, these resultatives appear to be derived through event composition. The compositionally derived nature of such resultatives receives support from the availability of paraphrases in (14) that made explicit reference to two events. The question, then, is how a single subevent analysis of such bare XP resultatives can be reconciled with the view that they involve event composition?

Events, as opposed to physical objects, are not individuated in the world. What in the complex flow of happenings in the world can be considered an event is a matter of construal, reflected in the properties lexicalized in verbs. We can say that a verb lexicalizes a set of properties which are temporally anchored and that a happening in the world with this set of properties is considered to be an event. We suggest that bare XP resultatives are compositionally derived in that the happening in the world that they describe involves two temporally anchored sets of properties 
which can each be lexicalized by a separate predicate; thus, this happening can potentially be conceptualized as involving two distinct events. Nonetheless, we argue that the relation between the constituent events-i.e., the two temporally anchored sets of properties-is tight enough that the two sets of properties can be conceptualized as being properties of a single event, allowing a simple event structure for bare $\mathrm{XP}$ resultatives. We say that bare $\mathrm{XP}$ resultatives are represented as simple events in event structure terms as a result of the COIDENTIFICATION of the constituent subevents. Our choice of the term "event coidentification" for the relationship that holds between events that are distinct in terms of conceptual structure-i.e., that can potentially be lexicalized separately-but that can be represented as a single simple event in event structure terms reflects the nature of this relationship. We argue that this relationship bears certain hallmarks of the notion "event identity," as it is discussed in the philosophy and linguistics literature (Davidson 1969; Lombard 1986; Parsons 1990; among others).

Drawing on this literature, we isolate several conditions which we propose are required for event coidentitification; these are presented in (30).

a. The subevents must have the same location and must necessarily be temporally dependent.

b. One subevent must have a property that serves to measure out that subevent in time; this property is predicated of an entity that is necessarily a participant in both subevents.

The first condition incorporates an essential condition on event identity discussed in the philosophy and linguistics literature (Davidson 1969; Parsons 1990; among others): events are spatiotemporally defined entities, and so to be identical, two events must have the same spatial and temporal properties. However, as noted in the literature on event identity, shared temporal extent alone is not sufficient for event identity. We propose that coidentified events must be temporally dependent, that is, unfold at the same rate. We suggest condition (30b) as a way to ensure that temporal dependence holds. There have been a number of interrelated approaches to the characterization of how events unfold in time (Dowty 1991; Hay, Kennedy, and Levin this volume, Jackendoff 1996; Krifka 1989, 1992; Ramchand 1997; Tenny 1987, 1994; Verkuyl 1993; among others). We build on this previous work, adopting the perspective in Hay, Kennedy, and Levin (this volume) that what is crucial to characterizing the temporal unfolding of an event is the existence of property of a participant in the event which reflects the temporal progress of the event as a whole, recognizing that the nature of this property is dependent on the type of event. For motion events, the property is the path of motion; for change of state events, the property is a gradable property related to the state itself; for events of consumption and creation, the property is the spatial extent of the created or consumed object. In bare XP resultatives, the subevent introduced by the result XP is the event that has the associated property. Given the nature of such resultatives this property is predicated of a participant in both subevents, and we propose that it is by virtue of this shared participant that the subevents are temporally dependent. 
We now consider an example. The bare XP resultative (31) portrays a happening in the world which involves the property of dancing and the property of traversing a path out of the room-the latter being a property that is not lexically entailed by the verb dance.

\section{Robin danced out of the room}

These properties can be lexicalized by two distinct verbs and thus can potentially be conceptualized as involving two events, as in (32), where they are expressed in distinct clauses each headed by its own verb.

Robin went out of the room dancing.

However, since the two events-i.e., the two temporally anchored sets of lexicalized properties-meet the conditions on event identity, their descriptions may be coidentified, and the happening is construed as a single event. That is, the properties of dancing and of traversing a path out of the room are considered properties of the same event. One possible formalization of what it means for two events to be coidentified is that the two lexical heads which lexicalize the properties of the two events are predicated of the same event variable, as in the Parsons-style 1990 representation in (33).

( $\exists$ e)[Dancing(e) \& Agent(e,Robin) \& Go-Out(e) \& Source(e,the room)]

In contrast, reflexive resultatives portray happenings in the world that need not be temporally dependent and thus do not show the temporal properties needed for construal as a single event. For example, in the reflexive resultative (34a), the properties of Robin's becoming stiff and of Robin's dancing cannot be considered properties of the same event since they do not meet conditions for event identity. They are at best only accidentally temporally coextensive and need not have the same temporal extent at all. Although there is a property in the result subevent (degree of stiffness) predicated of the dancer which is a participant in both subevents, it appears that the result XPs in this and other reflexive resultatives do not necessarily pick up on properties that are relevant to the temporal unfolding of events of the type specified by the verbs in these reflexives. (See Wechsler 1997 for similar ideas.) Therefore, the dancing and the becoming stiff can be construed as one event only via a complex event structure comprised of two subevents. If the reflexive resultative in (34a) were given a Parsons-style event structure, it would have two distinct subevents, as in (34b).

(34) a. Robin danced herself stiff.

b. $\quad(\exists e 1)(\exists e 2)[D a n c i n g(e 1) \&$ Agent(e1,Robin) \& Become-Stiff(e2) \& Theme(e2,Robin) \& Cause (e1,e2)] 


\section{Why Event Coidentification Takes Place}

One additional question remains to be addressed: Why MUST event coidentification take place when the appropriate conditions are met? That is, why is it quite marginal to express a happening in which Robin danced and by dancing also went out of the room using the reflexive resultative pattern, as in (35)?

(35) ?? Robin danced herself out of the room.

The oddness of this example demands an explanation since the subevents, though temporally dependent, do meet the general constraints on the relations between the subevents of a causative event laid out in (29). That is, if the temporally anchored properties lexicalized by the two lexical heads are construed as being predicated of two distinct events, then the relation between these events meet the constraints in (29). We suggest that such examples are not ungrammatical; rather, pragmatic considerations favor bare XP resultatives over reflexive resultatives as the expression of such happenings. The reason, we suggest, is that, all other things being equal, the preferred expression of a situation is the one that gives it the "tightest" event construal. Since a situation in which someone danced and thereby left the room can be construed as a single simple event, this construal is preferred to one in which the properties are factored out into two distinct subevents. Consequently, this happening will be expressed using the bare XP pattern. More generally, we propose that events which can be coidentified must be, a requirement which we argue follows from Grice's (1975) Maxim of Quantity, as we now explain. (See Horn 1996 and Krifka 1989 for a discussion of similar phenomena along these lines.)

McCawley (1978) proposes that pragmatic considerations can influence how a speaker chooses to express a particular situation, using causative situations as an example. As is well known, many languages have two formal means of expressing causative situations, typically known as lexical and periphrastic causatives; these are illustrated in (36).

(36) a. Terry opened the door. (Lexical Causative)

b. Terry caused the door to open. (Periphrastic Causative)

Distinct meanings are attributed to the two types of causatives: lexical causatives are said to describe direct causation, while periphrastic causatives are said to describe indirect causation. McCawley argues that this characterization is not quite correct; rather lexical causatives necessarily express direct causation, while periphrastic causatives are neutral with respect to directness of causation. To support this proposal, McCawley shows that periphrastic causatives can, in fact, describe either direct or indirect causation, using the following example to make his point. Suppose that Black Bart shot the sheriff to death-a clear instance of direct causation. In this context the question in (37) must be answered Yes, showing that direct causation comes under the scope of the periphrastic causative.

(37) Did Black Bart cause the sheriff to die? Yes/*No, he shot him through the heart and the sheriff died instantly. (McCawley 1978:250, (6b)) 
McCawley then argues that the typical restriction of periphrastic causatives to indirect causation follows from principles of conversational implicature. A speaker will use a lexical causative, if there is one available, to describe an instance of direct causation since by Grice's (1975) Maxim of Quantity this is more informative than using a periphrastic causative.

Similar considerations can be extended to the resultative construction. We have argued that in the bare XP resultatives, two sets of temporally anchored properties are conflated into a single event description with only one subevent in the associated event structure. However, the relation between these two sets of properties meets the constraints laid out in (29) on the relation between the subevents of reflexive resultatives. The first two constraints, (a) and (b), clearly hold. Furthermore, in (31), Robin danced out of the room, there is a counterfactual relation between the properties of an event of dancing by Robin and the properties of an event of traversing the path out of the room by Robin (constraint $\mathrm{c}$ ), since if Robin had not danced, she clearly would not have gotten out of the room, all other things being equal. This relation accounts for the causal flavor of this example and others like it, and, perhaps, for why they are sometimes considered causatives (see section 2.2). And since the dancing and the traversal of the path unfold together in (31), there is clearly no other intervening event in the causal chain between these events, so causation is direct (constraint d). Finally, the temporal relation between the dancing and the traversal of the path-that of temporal dependence-is really a special case of the temporal relation between the subevents in a causative event structure. As argued in section 2.3, bare XP resultatives must describe events with temporally dependent subevents, while reflexive resultatives are neutral as to the temporal dependence of the subevents in the events they describe; as we put it, the events need not be temporally dependent. As a result, the situations which can be described by the bare $x p$ resultatives are a subset of those which can be described by the reflexive resultatives. The use of a bare XP resultative, then, is more informative than the use of the reflexive resultative. In this way the relation between bare XP resultatives and reflexive resultatives resembles that between direct causatives and indirect causatives. Thus, a bare XP resultative should be preferred to a reflexive resultative in the expression of coidentified-i.e., necessarily temporally dependent-events, all other things being equal. As a result, reflexive resultatives will generally be restricted to the description of temporally independent events; therefore, (35) is disfavored on pragmatic grounds.

On this approach, then, whether or not two sets of properties are factored out and predicated of two distinct events or conflated to be predicated of a single event is in some instances a matter of choice between alternative conceptualizations of an event. Pragmatic considerations determine which conceptualization, and concomitantly which mode of expressing an event, is preferred. Thus, reflexive resultatives could be used to describe two temporally dependent events when pragmatic considerations disfavor the use of the bare XP resultative pattern. Consider one of the central uses of the bare XP pattern: to express motion in some manner towards a goal. The use of the reflexive resultative pattern to express such events would draw the hearer's attention to the component events. In fact, our collection of 
naturally-occurring resultatives includes at least two examples similar to the constructed example (35); the first one, (38a), describes a pampered cat, the second, (38b), an ex-husband who drops in on his former wife.

(38) a. Domina implied that her hunger was so debilitating that she could hardly crawl her sleek self across the kitchen floor. (J.R. Hulland, An Educated Murder, St. Martin's, New York, 1986, p. 156)

b. Then, without another word, he withdrew from the kitchen and sauntered his Bermuda-shorted self through the front door. (D.M. Davidson, Killer Pancake, Bantam, New York, 1995, p. 63)

Strictly speaking, these two examples are not instances of the reflexive pattern in that they have a modifier "inserted" into a reflexive pronoun rather than the reflexive pronoun characteristic of the reflexive resultative pattern; thus, they could be said to represent a variant of the reflexive resultative pattern. ${ }^{7}$

We believe that this slight departure from the reflexive resultative pattern is significant. As has often been noted (e.g., Croft 1991; Talmy 1976), animate entities can be presented as intentional agents - their prototypical construal-or as physical, and thus manipulatable, objects. The examples in (38) exploit the two perspectives on the entity whose motion is being described: as an intentional agent in subject position and as a physical object in postverbal position. ${ }^{8}$ The physical object construal is signaled by the use of a modifier describing physical appearance: sleek for the cat and Bermuda-shorted for the man. (That is, the modifiers could easily have referred to properties of an intentional agent, such as cunning for the cat or callous for the man, but they do not.) By choosing to use this variant on the reflexive resultative pattern to express these happenings rather than the bare XP pattern, the writers draw attention to the two conceptually distinct events that are being composed. Thus, they are able to convey that in (38a) there is substantial effort involved in the cat getting to the food and that in (38b) the protagonist is trying to create a certain effect by his exit.

In the discussion of the minimal pairs involving verbs such as wiggle and wriggle in (25)-(26) in section 2.3, we mentioned that not all such pairs are explainable in terms of a difference in whether or not the subevents described are necessarily temporally dependent. In those instances where both members of the pairs arguably involve temporally dependent subevents, the choice between the two resultative patterns might reflect pragmatic considerations. For instance, such considerations might illuminate a minimal pair involving the verb kick, which resembles the wiggle/wriggle minimal pairs in (25)-(26), but does not seem amenable to the account proposed for these pairs.

(39) a. A bantam chick kicks free from its shell. (Picture caption, Chicago Tribune, March 21, 1996, p. 8)

b. “... They ... watched a duckling kick itself free of its shell ..." read a newspaper report of the outing. ("Pellatt Lost Estate Farm to Stock Crash,” The Toronto Star, August 8, 1991, p. N4) 
The pair in (39) cannot be explained in the same way as the wiggle/wriggle pairsthat is, by appealing to differences in the situation being described-since the sentences in (39) describe precisely the same situation: a chick hatching. Furthermore, this situation involves two inherently temporally dependent subevents: the chick's kicking and the chick's becoming free from its shell. Since these subevents are potentially coidentifiable, they should be expressed via the bare XP pattern, as they are in (39a). We propose that the author chose the unexpected use of the reflexive resultative pattern in (39b) to draw the reader's attention to the larger point being made in this part of the article. This example is taken from a description of the new experiences of some "city girls"-a group of Girl Guides from Toronto-on a visit to a farm. By using the reflexive resultative pattern, the writer highlights the two distinct subevents involved, conveying that the girls are witnessing a chick's hatching for the first time.

\section{Conclusions and Consequences}

This paper uses resultative constructions based on intransitive verbs as a probe into the nature of compositionally derived events. We have shown that there are two ways of extending the basic meaning of a verb via event composition, resulting in two types of event structures: (i) a complex event structure consisting of two causally related subevents and (ii) a simple event structure formed from the composition of two necessarily temporally dependent "coidentified" events. Significantly, event composition does not always result in a causative event structure with two subevents. Only the first of the two types of event composition gives rise to a causative event structure, even though the counterfactual relation which defines causatives seems to hold between the "subevents" in bare XP resultatives, which we argue should nevertheless have a simple event structure. It seems natural language prefers to reserve true complex event structures for the representation of single events consisting of clearly distinct subevents, that is, subevents that do not meet the conditions on event coidentification. We have also argued that the two syntactic resultative patterns found with intransitive verbs are manifestations of the two event structures we have identified. Thus, the nature of a compositionally derived event is reflected in the syntax, with complex event structures requiring two arguments in their syntactic realization, following the Argument-Per-Subevent Condition. ${ }^{9}$

\section{Endnotes}

* We have had various opportunities to present this material, and we thank the audiences for their helpful questions and comments. We are also grateful to all those who have discussed this work with us or commented on the larger, unpublished manuscript that much of the content of this paper is drawn from, especially Edit Doron, David Dowty, Chris Kennedy, Fred Landman, Susan Rothstein, and Steve Wechsler. This work was supported in part by NSF Grant SBR-9616453 to Levin. 
1. Throughout this paper, we take the term "event" to refer to a happening in the world which is described by a verb and its complements or by a light verb with a predicative complement (e.g., become sick) and its complements. The term "event" is also used, however, to refer to the linguistic entity which describes this happening in the world, also called an event structure representation, to be introduced and illustrated in section 2.1. In discussing the notion of event composition, it is clear that we are not talking about composing the entities in the world, but rather forming a complex event description via an operation on event structures. Despite the inaccuracy of this term, we will continue to talk about event composition.

2. Although we label some of our event structures with traditional lexical aspectual labels, the difference between complex and simple events cannot be reduced to any recognized aspectual distinction. For example, a simple event structure can be telic (e.g., achievements with a definite change of state such as arrive) or atelic (e.g., activities such as run and indefinite change of state verbs such as dim); complex events can be telic (e.g., the resultatives under discussion) or atelic (e.g., some lexical causatives such as fly a kite). For more discussion see Van Valin and LaPolla 1997 and Hay, Kennedy, and Levin this volume. Another point worth mentioning is that not all researchers use the same criteria for assigning a complex event representation. Pustejovsky $(1991,1995)$ and van Hout (1996), for example, assign a complex event structure to all events which they consider transitions; for them the notion "cause" plays no part in the definition of complex events. Interestingly, they nevertheless do not assign distinct event structures to the two types of compositionally derived events that are the subject of this paper. A comparison of the various approaches is clearly in order.

3. In Rappaport Hovav and Levin 1998, this condition is not explicitly formulated, but rather its effects follow from the interaction of the inventory of possible event structures with a well-formedness condition on argument realization, the Structure Participant Condition. This condition requires that any participants explicitly required by the event structure be realized in the syntax; a simple event has one required participant, and a complex event has two. For ease of exposition we have formulated the Argument-Per-Subevent Condition here.

4. Goldberg (to appear) correctly points out that verbs of change of state are sometimes found with understood, but unexpressed, objects. However, as Goldberg herself notes, the objects of such verbs are omitted only under special conditions: for instance, when these verbs are found in generic or habitual contexts. These contexts also license unexpressed objects for verbs of surface contact and motion and other transitive verbs having an event structure with a single subevent, and it may be that the omission of direct objects in these contexts represents a different phenomenon from the one discussed here, which is precluded for verbs of change of state. Thus, it appears that the differences which we take to characterize the two classes of verbs remain valid, though the additional type of unexpressed object requires further investigation and must be accommodated within our theory of argument realization.

5. We are using the term "resultative construction" only for descriptive convenience and provide no explicit criteria for a sentence being an instance of this construction, so whether or not this pattern is considered a case of the resultative construction is 
not important for us. As we mention below, our interest in these examples stems from the fact that in some of these cases they involve event composition.

6. Nonsubcategorized NP resultatives show the same temporal relation between their subevents as reflexive resultatives: the subevents need not be necessarily temporally dependent. For example, in Leslie sneezed the tissue off the table, the tissue need not start moving until the sneeze is over. Given their syntactic form, these resultatives presumably have the same complex event structure as reflexive resultatives, as suggested in Rappaport Hovav and Levin 1999.

7. Our collection of resultatives includes further examples of verbs of manner of motion followed by a reflexive and a directional phrase; however, some of these may be simple causatives with a reflexive object rather than reflexive resultatives. In limited circumstances, English allows causatives of manner of motion verbs, as in I marched the kids out of the room, which receives the interpretation 'I caused the kids to march out of the room' and not the "resultative" interpretation 'I marched and thereby caused the kids to go out of the room'. Thus, sentences such as $I$ marched myself into the Harvard Bookstore... (S. Kelly, The Trail of the Dragon, Walker, New York, 1988, p. 88) must be evaluated carefully to determine whether they are causatives or reflexive resultatives. The sentence just cited would be paraphrased as 'I caused myself to march into the bookstore' on the causative analysis and as 'I marched, thereby causing myself to go into the bookstore' on the reflexive resultative analysis. The examples in (38) contain verbs which do not readily appear as causatives with nonreflexive objects $\left({ }^{*}\right.$ The cat crawled the kitten, ${ }^{*}$ He sauntered his child) and are likely to be reflexive resultatives rather than causatives.

8. The portrayal of an animate entity as a physical object is clear in the following nonsubcategorized NP resultative based on the intransitive verb fly: '... It [ =love] seized me in its talons and flew me up to the heavens ...' (H. Hucker, Trials of Friendship, St. Martin's, New York, 1998, p. 193).

9. As we discuss in Rappaport Hovav and Levin 1999, the question of whether unaccusativity is syntactically encoded can be fruitfully reexamined in light of this study. The explanation of the contrast between reflexive and bare XP resultatives has been at the core of arguments for the syntactic encoding of unaccusativity in English (Levin and Rappaport Hovav 1995; Simpson 1983; among others). In elucidating the nature of compositionally derived events, we have presented a semantic account of those facets of the resultative construction. Thus, our work further weakens the case for the syntactic encoding of unaccusativity in English, supporting previous arguments to this effect (e.g., Dowty 1991; Kaufmann 1995a, 1995b; Napoli 1988; Van Valin 1990; Wechsler 1997).

\section{References}

Bresnan, J. and A. Zaenen (1990) "Deep Unaccusativity in LFG," in K. Dziwirek, P. Farrell and E. Mejías-Bikandi, eds., Grammatical Relations: A CrossTheoretical Perspective, CSLI Publications, Stanford, CA, 45-57. 
Carrier, J. and J.H. Randall (1993) "Lexical Mapping," in E. Reuland and W. Abraham, eds. (1993), 119-142.

Croft, W.A. (1991) Syntactic Categories and Grammatical Relations, University of Chicago Press, Chicago, IL.

Davidson, D. (1969) "The Individuation of Events," in N. Rescher, ed., Essays in Honor of Carl G. Hempel, Reidel, Dordrecht, 216-234.

Dowty, D.R. (1979) Word Meaning and Montague Grammar, Reidel, Dordrecht.

Dowty, D.R. (1991) "Thematic Proto-Roles and Argument Selection," Language 67, 547-619.

Gawron, J.M. (1985) “A Parsimonious Semantics for Prepositions and CAUSE," Papers from the Parasession on Causatives and Agentivity, CLS 21, Part 2, Chicago Linguistic Society, Chicago, IL, 32-47.

Goldberg, A.E. (1995) Constructions: A Construction Grammar Approach to Argument Structure, University of Chicago Press, Chicago, IL.

Goldberg, A.E. (to appear) "The Varied Distribution of Causative Verbs: Omitted Arguments and Secondary Predicates," Linguistic Sciences.

Grice, H.P. (1975) "Logic and Conversation," in P. Cole and J. Morgan, eds., Syntax and Semantics 3: Speech Acts, Academic Press, New York, 41-58.

Grimshaw, J. and S. Vikner (1993) "Obligatory Adjuncts and the Structure of Events," in E. Reuland and W. Abraham, eds. (1993), 143-155.

Hay, J., C. Kennedy, and B. Levin (this volume) "Scalar Structure Underlies Telicity in 'Degree Achievements'."

Hoekstra, T. (1984) Transitivity, Foris, Dordrecht.

Hoekstra, T. (1988) "Small Clause Results," Lingua 74, 101-139.

Horn, L.R. (1996) "Presupposition and Implicature," in S. Lappin, ed., The Handbook of Contemporary Semantic Theory, Blackwell, Oxford, 299-319.

van Hout, A. (1996) Event Semantics of Verb Frame Alternations, Doctoral dissertation, Tilburg University, Tilburg, The Netherlands.

Jackendoff, R.S. (1990) Semantic Structures, MIT Press, Cambridge, MA.

Kaufmann, I. (1995a) "O- and D-Predicates: A Semantic Approach to the Unaccusative-Unergative Distinction," Journal of Semantics 12, 377-427.

Kaufmann, I. (1995b) "What is an (Im-)possible Verb? Restrictions on Semantic Form and their Consequences for Argument Structure," Folia Linguistica 24, 67-103.

Kaufmann, I. and D. Wunderlich (1998) “Cross-linguistic Patterns of Resultatives," unpublished ms., University of Düsseldorf, Düsseldorf, Germany.

Kenny, A. (1963) Action, Emotion, and Will, Routledge and Kegan Paul, London.

Krifka, M. (1989) "Nominal Reference, Temporal Constitution and Quantification in Event Semantics," in R. Bartsch, J. van Benthem, and P van Emde Boas, eds., Semantics and Contextual Expression, Foris, Dordrecht, 75-115.

Krifka, M. (1992) "Thematic Relations as Links Between Nominal Reference and Temporal Constitution," in I.A. Sag and A. Szabolcsi, eds., Lexical Matters, CSLI Publications, Stanford, CA, 29-54.

Levin, B. and M. Rappaport Hovav (1995) Unaccusativity: At the Syntax-Lexical Semantics Interface, MIT Press, Cambridge, MA. 
Lewis, D. (1973) “Causation,” The Journal of Philosophy 70, 556-567.

Lombard, L.B. (1986) Events: A Metaphysical Study, Routledge and Kegan Paul, London.

McCawley, J.D. (1971) "Prelexical Syntax," Report of the 22nd Annual Roundtable Meeting on Linguistics and Language Studies, Georgetown University Press, Washington DC, 19-33.

McCawley, J.D. (1978) "Conversational Implicature and the Lexicon," in P. Cole, ed., Syntax and Semantics 9: Pragmatics, Academic Press, New York, 245259.

Napoli, D.J. (1988) “Review of L. Burzio: Italian Syntax,' Language 64, 130-142.

Parsons, T. (1990) Events in the Semantics of English, MIT Press, Cambridge, MA.

Pesetsky, D. (1995) Zero Syntax, MIT Press, Cambridge, MA.

Pinker, S. (1989) Learnability and Cognition: The Acquisition of Argument Structure, MIT Press, Cambridge, MA.

Pustejovsky, J. (1991) “The Syntax of Event Structure,” Cognition 41, 47-81.

Pustejovsky, J. (1995) The Generative Lexicon, MIT Press, Cambridge.

Ramchand, G.C. (1997) Aspect and Predication, Clarendon Press, Oxford.

Rapoport, T.R. (1998) "Structure, Aspect, and the Predicate," unpublished ms., Ben-Gurion University, Beer-Sheva, Israel.

Rappaport Hovav, M. and B. Levin (1998) "Building Verb Meanings," in M. Butt and W. Geuder, eds., The Projection of Arguments: Lexical and Compositional Factors, CSLI Publications, Stanford, CA, 97-134.

Rappaport Hovav, M. and B. Levin (1999) "A Reevaluation of The Direct Object Restriction on English Resultatives," unpublished ms., Bar Ilan University and Northwestern University, Ramat Gan, Israel and Evanston, IL.

Reuland, E. and W. Abraham, eds. (1993) Knowledge and Language II: Lexical and Conceptual Structure, Kluwer, Dordrecht.

Roberts, I.G. (1988) "Predicative APs," Linguistic Inquiry 19, 703-710.

Shibatani, M. (1976a) Syntax and Semantics 6: The Grammar of Causative Constructions, Academic Press, New York, NY,

Shibatani, M. (1976b) "The Grammar of Causative Constructions: A Conspectus," in M. Shibatani, ed. (1976a), 1-40.

Simpson, J. (1983) "Resultatives," in L. Levin, M. Rappaport and A. Zaenen, eds., Papers in Lexical-Functional Grammar, IULC, Bloomington, IN, 143-157.

Talmy, L. (1976) "Semantic Causative Types," in M. Shibatani, ed. (1976a), 43116.

Tenny, C.L. (1987) Grammaticalizing Aspect and Affectedness, Doctoral dissertation, MIT, Cambridge, MA.

Tenny, C.L. (1994) Aspectual Roles and the Syntax-Semantics Interface, Kluwer, Dordrecht.

Van Valin, R.D., Jr. (1990) “Semantic Parameters of Split Intransitivity," Language 66, 221-260.

Van Valin, R.D., Jr. and R.J. LaPolla (1997) Syntax: Structure, Meaning and Function, Cambridge University Press, Cambridge, UK. 
Verkuyl, H. (1993) A Theory of Aspectuality, Cambridge University Press, Cambridge, UK.

Wechsler, S. (1997) "Resultative Predicates and Control," Texas Linguistic Forum 38: The Syntax and Semantics of Predication, Department of Linguistics, University of Texas, Austin, TX, 307-321.

Wunderlich, D. (1997a) “Argument Extension by Lexical Adjunction,” Journal of Semantics 14, 95-142.

Wunderlich, D. (1997b) “Cause and the Structure of Verbs," Linguistic Inquiry 28, 27-68. 